\title{
ARTESANIA E INDUSTRIA DEL CALZADO EN VALVERDE DEL CAMINO (HUELVA)
}

\author{
María de la Luz PARREÑO HIDALGO*
}

\section{INTRODUCCION}

El análisis de la transformación de una primitiva artesanía general, en una industria especializada dentro de los sectores del mueble y, especialmente, del calzado, me llevaron a buscar unos orígenes de estas actividades, pero argumentos cientificos del cambio nadie pudo aportar.

No posibilitaríamos un estudio completo sin acercanos a los primeros datos escritos de esta población, que aparecen en el año 1469, cuando todavía era una aldea llamada Facanías, «el nombre del dueño de la Venta que existió en el Valle verde del Camino, entre la Cuenca minera y Huelva» y contaba con diez vecinos y sus familias, es decir, unas cuarenta o cincuenta personas.

Valverde del Camino es un municipio, en la actualidad, de $218,46 \mathrm{~km}^{2}$, extensión alcanzada en el año 1971. Está situado en la parte oriental de la franja central de la provincia de Huelva. Su término limita al N. con el de Zalamea la Real, que se expande hacia el E.; al O. con el de Calañas y Beas; al S. con el de Beas y Niebla y al E. con el de Niebla y Zalamea la Real.

Hasta 1971, fecha en que se ganó el último de los pleitos mantenidos con Niebla, la extensión municipal de Valverde era de $185 \mathrm{~km}^{2}$, pequeña en comparación con la de otros municipios colindantes. A pesar de su escaso término los valverdeños, durante la Edad Moderna y Contemporánea, disfrutaron de una abundante ganadería respecto a los demás pueblos; pero no así en lo relativo a la agricultura, pues las tierras no son fértiles, salvo, aproximadamente, un $10 \%$ del territorio. Esta realidad geográfico-económica impulsó la ocupación de terrenos en los llamados «baldíos» de Niebla, que utilizaban comunalmente junto con otras poblaciones, también pertenecientes al antiguo condado iliplense. Esta situación provocó una serie contínua de pleitos, que siempre

* Licenciada en Geografía e Historia. 
ganaron los valverdeños en la Chancillería de Granada, hasta llegar al último en que se ha conseguido la ampliación por la zona este del pueblo, a expensas de los terrenos comprendidos entre el km. 5 y el km. 19 de la carretera Valverde-La Palma del Condado, pertenecientes a los términos municipales de Zalamea y Niebla.

\section{FIGURA 1}

PIRAMIDE DE POBLACION DE VALVERDE DEL CAMINO

INTERVALOS DE EDAD

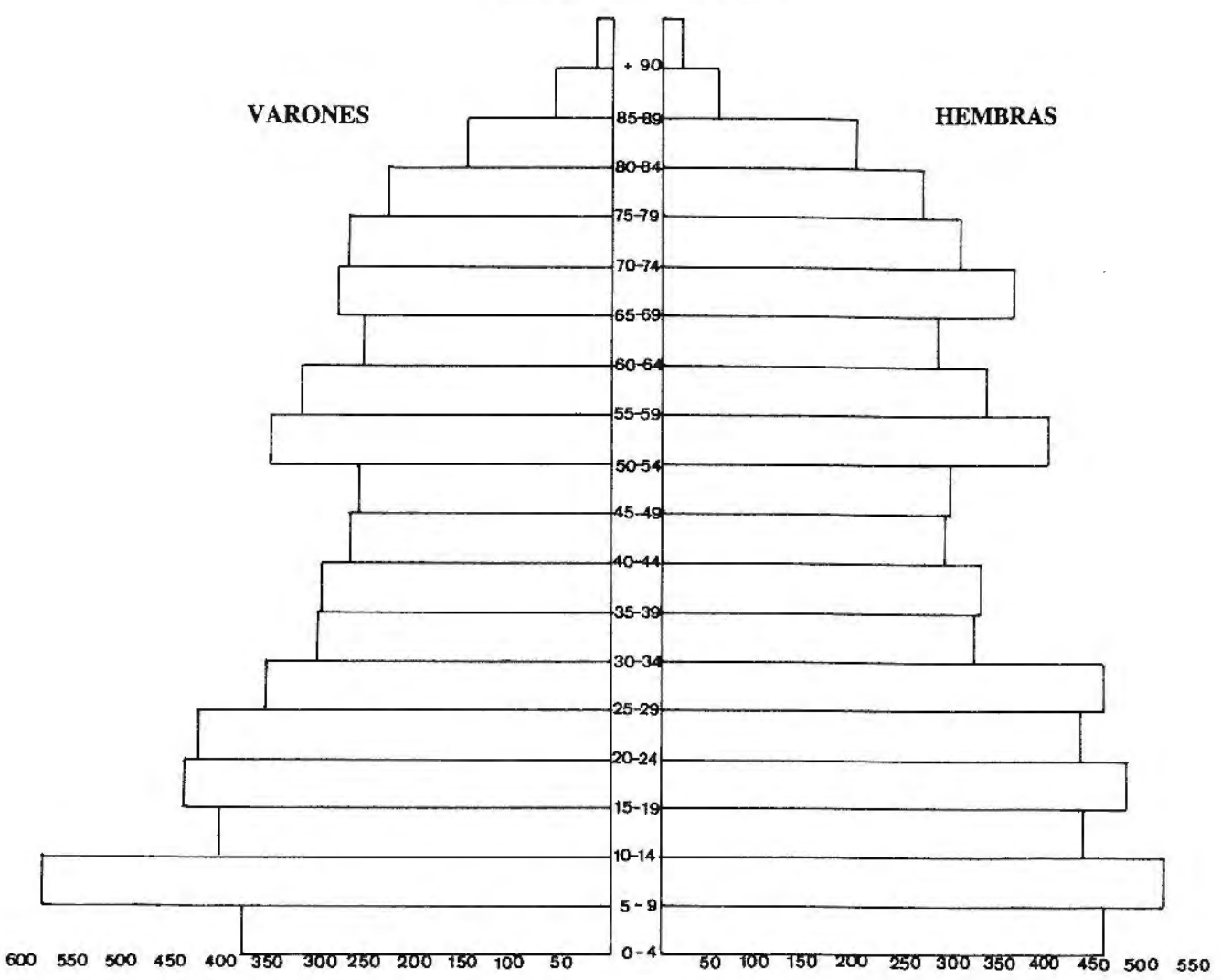

\section{ORIGEN DE LA INDUSTRIA}

Valverde ha sido siempre zona de paso, entre el norte minero y el sur agrícola y pesquero de la provincia onubense. Para satisfacer la demanda de productos manufacturados del norte y del sur, en la capital del municipio, situada 
casi en el centro del término, a $37^{\circ} 37^{\prime}$ de latitud N. y a $6^{\circ} 53^{\prime}$ de longitud O., se desarrollaron telares, talleres de forja, de zapatos, fábricas de harinas a base de molinos de agua, etc.

La actividad más desempeñada fue la manufactura de zapatos, había más oferta que demanda, y alcanzó un mayor auge a partir de la creación del ferrocarril minero Buitrón-San Juan del Puerto (el primero de los construidos en la provincia de Huelva) en 1868.

La construcción ferroviaria fue una de las empresas acometidas durante la 2. ${ }^{a}$ mitad del siglo XIX, por compañías extranjeras, sobre todo inglesas, pues es la época de mayor poder económico del imperio inglés y de su industria. Es cuando vuelve a resurgir la minería onubense. Se producen pues cambios en la geografía de la provincia, como son la aparición de nuevos poblados mineros y la transformación de poblaciones agrícolas y ganaderas en artesanales e industriales.

Así ocurrió en Valverde, donde un grupo inglés construyó y explotó el ferrocarril y llevó la dirección de varias minas. No fue muy numeroso, pero se mantuvo durante casi 100 años. Sus miembros no estuvieron aislados como en otras comunidades inglesas de la provincia, sino que en general contactaron con los nativos, vivieron en el pueblo y algunos de ellos llegaron a casarse con valverdeñas.

La llegada de la compañía inglesa con sus ferrocarriles trajo consigo una mayor facilidad para el traslado y venta de los productos artesanales por pueblos y minas, facilitó la adquisición de maquinaria, la llegada de nuevas materias primas, la facturación a San Juan de Puerto de los productos manufacturados y en definitiva supuso un desarrollo importante en la economía local y un despegue notable respecto a los demás pueblos de la comarca, llegando incluso a cambiar el modo de vida de la población valverdeña, que de artesana terminó en industrial.

Durante este período los valverdeños no sólo se habitúan a tratar a estos extranjeros, sino que los aceptan y respetan. También supieron aprender de los ingleses, formándose bajo sus enseñanzas buenos administrativos, delineantes, mecánicos, electricistas, caldereros..., pero sobre todo, ellos inculcan a los valverdeños la seriedad, la organización, el método en el trabajo, el cumplimiento del horario, en suma, el amor por el trabajo bien hecho.

Como un hecho significativo a destacar señalemos la presencia en las pequeñas industrias locales de oficinistas y mecánicos de la compañía inglesa; éstos, a la salida del trabajo, dedicaban algunas horas diarias a la administración o reparación y conservación de la maquinaria del calzado. En muchos casos estos expertos formados por la compañía se independizan y utilizan su preparación y experiencia fuera de la misma. Así por ej. Manuel Santos Hidalgo y Juan Cejudo Fiscal, trabajadores de talleres montan el primer taller mecánico 
privado en Valverde, en el que no sólo se reparaban automóviles sino que llegaron a fabricar incluso calderas de esencia y máquinas de enfrenar para el calzado (sus descendientes llevan el actual taller de Citroén). A la fábrica INVAL (Industria Valverdeña) van como mecánicos Fernando Cejudo y José Feria, encargados de la reparación y conservación de la maquinaria de calzado. Y así otros muchos casos.

\section{EVOLUCION DE LA INDUSTRIA, SIGLOS XIX Y XX}

Hace unos doscientos años surgió la artesanía del calzado en Valverde y prueba de su desarrollo es que en 1873, Manuel Mantero Asuero ganó el Premio de la Exposición Internacional de Viena por la confección de un par de zapatos de señora.

El impulso primero y definitivo a esta incipiente artesanía lo dió la aparición del ferrocarril y de los medios de comunicación posteriores, que permitieron el desplazamiento de las «medidoras» es decir, las mujeres de los artesanos zapateros de últimos de siglo, que en los pueblos cercanos a Valverde tomaban medidas a los clientes, las enviaban a sus maridos y de esta forma ellos realizaban zapatos con «nombres y apellidos».

Pero es en 1912 cuando surge la primera fábrica mecánica de calzado, situada en la calle José Franco (nombre mantenido durante el gobiemo del general Franco) y en dos locales cuya propiedad corresponde hoy a la Cooperativa Muebles Valverde. La instalación corrió a cargo de la «Unión de Maquinaria para el Calzado, S.A.». Fue la primera fábrica mecánica que se montó en toda Andalucía y Extremadura. Contaba con el sistema «Good Year» (Empalmillado) y con el sistema «Blake» (cosido dentro y fuera). Esta fábrica estaba montada para una producción inicial de 400 pares diarios y se abrió dando ocupación a 160 obreros de ambos sexos. Su nombre era J.D.J. Arroyo y Cía S. en C. Poco antes de estallar la Primera Guerra Mundial cerró.

La segunda fábrica mecánica de calzado creada en Valverde fue «El Crédito Obrero, S.A.», en 1917, también estuvo ubicada en el mismo lugar de la primera.

En las instalaciones de las fábricas anteriores se funda en 1918 otra con el nombre de «Romero+Becerro y Cía.», de ésta surgiría en 1924 la «INVAL» (Industrial Valverdeña, S.A.), que hacia 1933 contaba con cerca de 225 empleados y se mantuvo hasta 1960. Es precisamente en 1924 cuando Manuel Romero Pérez obtiene el título de Patronista-Modelista del calzado, siendo el primero que lo hacía en Valverde. Esto supone una aportación de ideas y técnicas para quienes producían calzado: mejor ajuste del diseño a la anatomía 
del pie, aprovechamiento máximo de las pieles, posibilidad de utilizar mejor el auxilio que determinadas máquinas de cortar, coser, etc. prestaban a la artesanía.

Paralelamente a la industria del calzado y como auxiliar de la misma, surge la de «cortes aparados» ${ }^{1}$, que tuvo gran auge en Valverde, con unas diez empresas que daban trabajo a 300 personas; parte de estos cortes se enviaban a pueblos de Andalucía y Extremadura.

Los primeros años de la década de los 30 constituyen una de las etapas más florecientes. El calzado valverdeño se vendía en muchas ciudades españolas, en competencia con los fabricantes del Levante.

Durante la guerra civil, los centros fabriles del calzado en los Valles de Vinalopó, en la Vall de Uxó, etc. quedan en la zona republicana; Valverde, al estar en la «nacional», se ve obligada a fabricar calzado con materiales de peor calidad a precios más elevados, dada la escasez de materia prima. Fue un buen momento económico, pero el peor en cuanto a la calidad de la producción.

En cambio, son muy positivos los años 50, en los que Valverde exhibe por primera vez en una muestra el boto campero, con novedades respecto al tradicional, como son: la caña un poco más alta y el estar compuesto por dos piezas con dibujos de arabescos, diseñados por Manuel Parreño, hijo de su creador, José Parreño Lineros. Este es el boto que más éxito ha tenido a partir de los años 60 y aún más en los años 70 , que coincide con la etapa más floreciente del calzado valverdeño.

\section{LOCALIZACION DE LA INDUSTRIA ${ }^{2}$}

Más de la mitad de las industrias del calzado se sitúan dentro del casco urbano y próximas a las carreteras principales que atraviesan la población. Del resto, aproximadamente la mitad ocupa zonas de relativa equidistancia entre el centro urbano y las travesías. Tanto unas como otras llegan a sumar un total de 26 industrias.

Así pues, como zonas de mayor concentración industrial podríamos destacar: La zona sur, en torno a la carretera S. Juan-Cáceres, a la entrada de la población. La zona nordeste y por último la zona oeste, en las cercanías de la travesía de Calañas.

En definitiva, uno de los factores que más han primado en la localización industrial ha sido la facilidad de transporte y comunicación. Otro factor sería el poder obtener de forma más rápida y económica terrenos para la instalación y futuras ampliaciones de las industrias.

1. Aparar: Coser los zapateros las piezas de que se compone el zapato, antes de ponerle la suela.

2. Los datos sobre localización de industrias se han obtenido en la Delegación Provincial de Industria y conuprobado «in situ». 


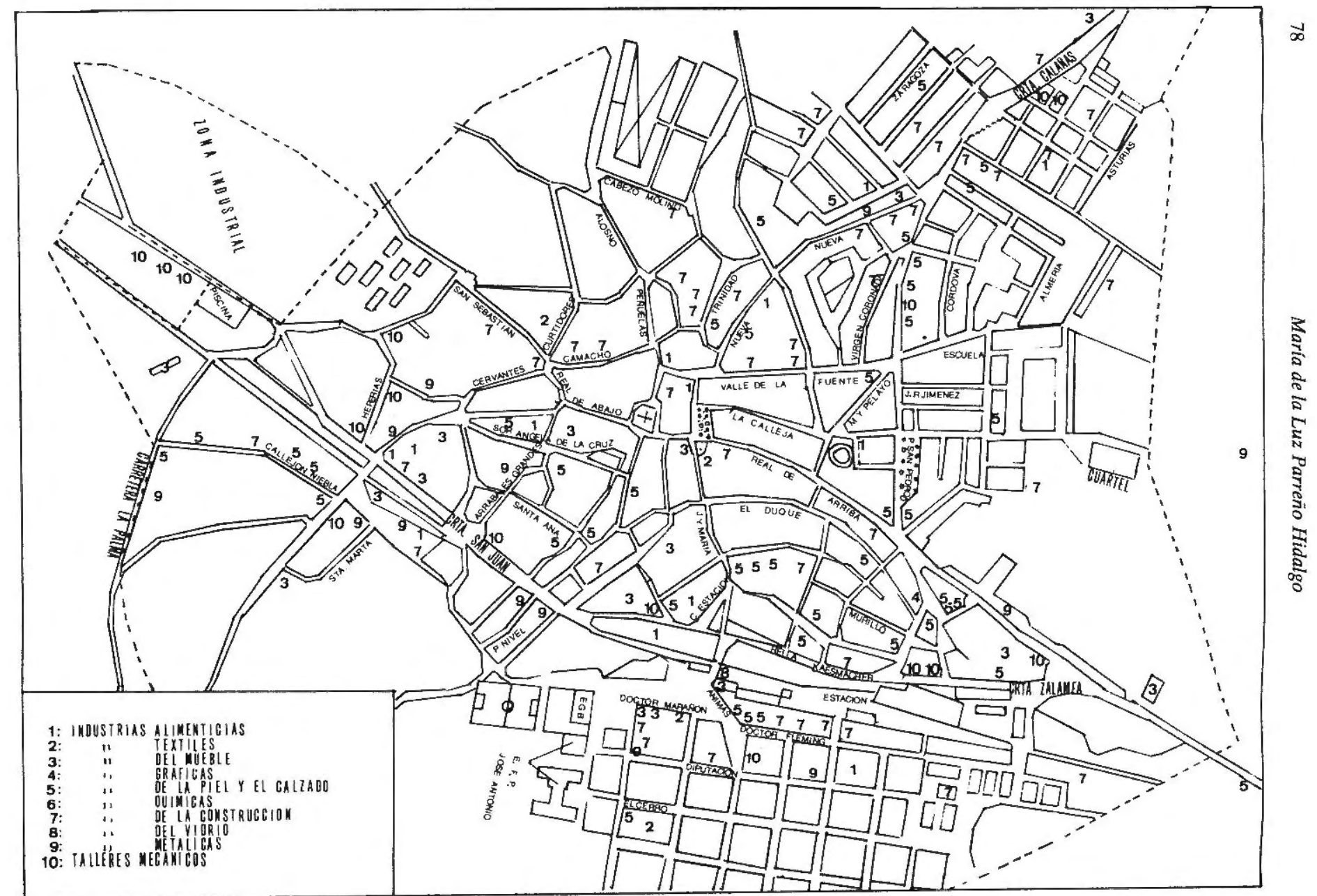

FIGURA 2. SECTORES INDUSTRIALES 


\section{DIMENSION Y DISTRIBUCION DE FRECUENCIA DE LAS EMPRESAS ${ }^{3}$}

Hay un predominio de la pequeña empresa (de 1 a 5 obreros), un $71,95 \%$ de las existentes responde a este grupo; que representa el 30,25\% del total de los obreros de la industria del calzado.

A la inversa ocurre con las empresas medianas (en intervalo entre 6 y 34 obreros), que ocupan un $60,82 \%$ de los trabajadores y sólo representa un $27,43 \%$ de las empresas.

Es escasa la presencia de la gran empresa (más de 34 obreros) tanto en número como en trabajadores: $0,6 \%$ y $8,91 \%$ respectivamente.

Analizada la distribución de frecuencias por sectores industriales, vemos que en todos los valverdeños predomina la pequeña empresa, a excepción de dos: el de la artes gráficas y el del calzado, en los que destaca la mediana (de 6 a 34 obreros).

De este modo, dado el predominio de la pequeña empresa, seguida de la mediana, es lógico plantearse la existencia en Valverde de un minifundismo industrial, hecho por otro lado generalizado en la industria española.

Hay que reconocer que la pequeña empresa tiene bastantes inconvenientes, debido sobre todo al escaso margen de inversión que le permite su reducida producción, y, en consecuencia, sus ajustados beneficios. Esto hace que la investigación industrial sea muy limitada y que Ja maquinaria utilizada no se pueda renovar según las exigencias. Tampoco se puede disponer del personal suficientemente preparado para dirigir, administrar y comercializar los productos. Tiene escasez de medios para la promoción de sus artículos, etc.

Respecto a este último punto mencionado, se puede citar como ejemplo la campaña publicitaria montada por 38 pequeños fabricantes de botos camperos, en la temporada 1978-79. Necesitaron unirse para poder hacer frente al coste total de la campaña (radio, prensa, T.V.E.).

En cambio, un aspecto positivo de la pequeña industria es la calidad, y, por tanto, la competitividad de sus productos, ya que su elaboración es en muchos casos semiartesanal (hecho comprobado en la mayoría de las industrias del calzado), siendo la materia prima empleada igualmente de calidad.

3. Con los mismos datos de la Delegación Provincial de Industria realizamos un estudio de la dimensión y distribución de la frecuencia de las empresas, del cual deducimos las anteriores conclusiones. 


\section{PROCESO DE FABRICACION DEL CALZADO}

El carácter artesanal ha estado vinculado a esta industria en Valverde, aunque en los últimos tiempos, por necesidad del mercado, se ha ido introduciendo nueva maquinaria.

El proceso de fabricación del boto puede dividirse en las siguientes fases: Cortado, Aparado y Montaje.

En la primera de ellas se cortan las pieles principales y los forros, aquellas se introducen en la máquina de moldear, después se rectifican errores y se rebajan los cantos de la piel; finalmente, el empaste o unión del forro a la piel principal con pegamento.

Para el Aparado, primero se hace el relleno o cosido del dibujo anteriormente impreso en la piel (es opcional) y posteriormente se unen las diversas piezas mediante costuras y vivos.

El Montaje o fabricación propiamente dicha depende del sistema que se emplee. Hay dos, el llamado Mixto, tradicional en la fabricación del boto campero valverdeño, y el sistema Good-Year o Empalmillado. Una de las principales diferencias entre los dos sistemas está en la unión del corte ${ }^{4}$ al piso en su parte interna. En el primero esta unión se realiza mediante clavos, y en el segundo por cosido. Por ello, este último tiene las ventajas de hacer más flexible y menos pesado al boto, además de evitar la oxidación por el agua. Es el que se utiliza en la fábrica "Valverdeña del Calzado, S.L.». El Montaje se puede resumir en las siguientes subfases:

- Preparación del Montaje, que consiste en la colocación de la planta, introducción de la horma y moldeado de traseras y delanteras.

- Después empieza el Montaje propiamente dicho o unión de las distintas partes del corte aparado a la planta. Esta operación es la más larga y laboriosa, en ella se utilizan tanto máquinas como la mano del hombre. Entre las diversas etapas destacan: el montado de las partes laterales («enfranques») y traseras; recorte de sobrantes; puesta de cerco o vira ${ }^{5}$; relleno del hueco que queda entre el cerco y la planta; pegado, recorte, punteado, asentamiento y embellecimiento («desvirado») de la suela; clavado y desvirado del tacón.

- Termina con el «finisaje» (acabado): tintado, lujado (dar brillo) y envasado del boto.

4. Corte se llama comúnmente en Valverde a las piezas del futuro calzado, cosidas y preparadas para unirle el piso.

5. La vira o cerco es una pieza alargada que se adapta al contorno del piso para que éste, a su vez, pueda ser cosido o clavado al corte y a la planta. 


\section{LAS MATERIAS PRIMAS}

La piel es el componente principal del calzado. De su adecuada elección depende la posterior calidad y mejor venta: dos elementos básicos para cualquier empresa. Este es el motivo por el que dedicamos un apartado al estudio de las materias primas en general y especialmente de la piel. Procede tanto de la cabaña nacional como de la importada (Francia y Argentina). Los almacenistas valverdeños la adquieren en Barcelona, Tarragona, Gerona, Valencia, Palencia, Albacete, Zaragoza y Sevilla. En Valverde no se cuenta hoy con ninguna fábrica de curtidos, aunque a primeros de este siglo hubo dos o tres curtidurías pequeñas, de tipo familiar, pero desaparecieron en los años de la postguerra. Igualmente surgió otra tenería (fábrica de curtidos) en 1950, llamada «Tenería Andaluza, S.A.», con una plantilla de 8 a 10 obreros, tuvo que cerrar en 1970.

Las pieles principales proceden del ganado ovino. Son las menos resistentes. Cuando su curtición es «al vegetal» ${ }^{6}$ reciben el nombre de badana y se utiliza sobre todo para forro, si la piel es pequeña; pero si es grande, se emplea para zurrones, mochilas... Es de color beige característico. Cuando su curtición es «al cromo» ${ }^{7}$ se le llama «metis» y puede tintarse con diversos colores: negro, azul... Su aplicación es variada y de mayor frecuencia.

Las caprinas o cabrías son mas fuertes y apreciadas que las ovinas. Según la edad del animal, la piel recige un nombre distinto; así tenemos de menor a mayor edad: «tafiletes», «cabritos», «dóngolas» y «cabras». Crece el valor cuanto menor es el animal, ya que sus poros son más finos y se dedican a calzado de lujo, billeteras...

De características y empleo similares a las caprinas son las de ciervo. Las de cerdo son pieles bastas de poro, debido a las cerdas, además son gruesas, lo que permite la obtención de distintas capas de «serraje» ${ }^{8}$. El «beige» es el color dominante, aunque se tonalizan en todos los colores. Se curten especialmente «al cromo», porque así resulta de mayor resistencia.

Las vacunas se diferencian según la edad del animal. Las mas gruesas y consistentes son las comprendidas entre el becerro y el animal adulto, por lo que se les puede extraer «serraje» para calzados, botas... Se realizan las dos curticiones de acuerdo con el destino de cada piel: «al vegetal», cuando su utilización es para botas de campo, sandalias, bolsos, carteras..., toman en todos estos casos el nombre de «becerro»; "al cromo», si se dedican a calzados y botas finas; adquiere tonalidades diferentes y dos nombres de acuerdo con el

6. Curtición a base de cortezas de árboles. La encina ha sido el árbol utilizado tradicionalmente.

7. Curtición química. Toma el nombre del elemento principal que interviene en todo el proceso.

8. La interior recibe el nombre de «serraje» propiamente dicho. Lo emplean en calzado económico. 
grosor de la piel resultante; «box-calf» y «tan-calf». La piel del animal joven, de 1 año (ternera), es la más valiosa, normalmente se curte «al cromo» y se emplea para calzado fino. Curtida «al vegetal» es dedicada a zahones, tipo romero, ganadero o de cacería.

La parte mas cotizada de las pieles equinas es la de las ancas del caballo. Se curte «al vegetal». La cara interior, no la tez, es la valorada, ya que aquella alcanza un brillo y bondad inmejorables. Especialmente se utiliza para botas finas.

Las demás pieles de estos animales se curten principalmente «al cromo», de colorido variado. Se les llama simplemente «caballos» y se emplean para calzado de señora y caballero.

Las de los bóvidos (búfalo, bisonte...) son pieles gruesas y bastas. Se dedican a botas, carteras, bolsos... Se curten «al cromo» o «al vegetal» y sus colores son variados.

Las pieles mas empleadas en Valverde son las vacunas para el exterior del calzado y las ovinas y porcinas para el forro.

Otras materias primas auxiliares tienen diversas procedencias. De Cataluña y Levante proceden el hilo, cordones, disolvente, hebillas, pegamento líquido, cartón, cajas plegables grandes. Los clavos y hebillas se adquieren en el País Vasco, así como los cordones en Zaragoza. El cartón y las cajas individuales se obtienen en el mismo Valverde del Camino. El pegamento sólido o cola termoplástica y clavos son adquiridos en Alemania.

\section{LAS EMPRESAS. ASPECTOS ECONOMICO, COMERCIAL Y LABORAL}

Las 24 industrias encuestadas, prácticamente las existentes, venden la mitad de su producción en el mercado interior español y la otra, en el exterior, del que destaca Italia como principal cliente.

La mayoría de las empresas $(62,5 \%$ ) se dedican a la fábricación especializada de un sólo artículo: el boto. Otras (20,83\%) tienen mayor variedad en su producción; de ellas, una abre mercados con la introducción del zapato llamado «todo terreno», fuerte, cosido, semiartesanal. El resto $(16,6 \%)$ se ha especializado casi exclusivamente en zapatos deportivos, zapatos de baile y ballet e incluso en prendas deportivas.

Las industrias dirigidas sobre todo al boto indican que la mejor época, tanto en producción como en beneficios, fue la década de los años 70. En 1978-79 se produjo una crisis, con un descenso rápido al principio y mediano después, hasta llegar al máximo en 1982. Posteriormente se suceden años buenos y malos, pero en general hay un incremento del consumo, pues se encuentran nuevos mercados (Italia). 
Un rasgo común de todos los empresarios es la escasa inversión en propaganda; el mayor capítulo de gastos es el empleado en la asistencia a ferias internacionales.

Un rasgo común de todos los empresarios es la escasa inversión en propaganda; el mayor capítulo de gastos es el empleado en la asistencia a ferias internacionales.

El boto es un artículo de invierno, por ello su fabricación se realiza durante el verano; al llegar el mal tiempo las industrias despiden a los obreros contratados temporalmente o hacen expediente de crisis. Esta práctica del contrato temporal es una medida habitual entre los fabricantes. Ha sido una forma de escapar a los problemas económicos y laborales llegados con la crisis del boto.

En esta industria es notable la presencia de la mujer $(19,27 \%)$; su participación sería mayor si se tuviese en cuenta el número de aparadoras que trabajan en su domicilio.

La presencia de obreros de edades comprendidas entre los 16 y 30 años es importante, pues, casi llega a la mitad del total.

\section{CONSIDERACIONES FINALES}

Valverde está apartado de los principales centros industriales del país: Levante y Cataluña, por ello dispone de pocas industrias auxiliares y es el último punto en servirse de las existentes en el NE peninsular. Los centros de consumo que le rodean no son significativos, pues Andalucía es una de las regiones más deprimidas. Podríamos hacer una excepción con Sevilla por su población, sin olvidar que, constituye capital, centro administrativo y comercial de Andalucía.

El empresario valverdeño no posee una contrastada y sólida formación técnica, económica y mercantil. La mayor parte de las fábricas son heredadas. Este hecho ha sido negativo para la capitalización de las industrias, pues por ejemplo en la década de los años 70 , que fue tan favorable para la fabricación de calzado, hubo empresarios que bajaron los precios y aceptaron letras de cambio, cuando lo normal es que hubiesen encarecido el producto ante la gran demanda. Al cambiar la moda no existieron posibilidades de subsistencia para muchas pequeñas industrias, y las restantes perdieron la oportunidad de haberse hecho con los últimos avances tecnológicos.

De todas formas el hombre de empresa valverdeño se crece ante las dificultades, a su nivel está bien capacitado y se esfuerza por aprender. Es notable en este aspecto el interés de los mismos en iniciarse en lenguas extranjeras.

Actualmente, la industria del calzado valverdeño se dedica en su mayor parte a un sólo artículo: el boto. Las ventas generales se reparten entre España 
e Italia sobre todo. Esta dependencia tan selectiva de artículo y mercado puede ser negativa. Ya se perdió parte del mercado nacional en la década de los 80 , pero se encontraron nuevos clientes en el exterior. Ante la posibilidad de nuevas pérdidas en el futuro se buscan soluciones y se pretende perfeccionar las utilizadas en otras ocasiones, como la publicidad, que no dió el resultado esperado.

Entre las posibles medidas que se apuntan se destacan las siguientes: Mayor variedad de artículos y un calzado fuerte, cosido por la suela y no pegado como en la zona levantina, de piso duro, semiartesanal. Es el realizado ya en algunas empresas valverdeñas con excelentes resultados.

Unidad entre varios fabricantes para la comercialización o para cualquier otra fase de la producción. Un ejemplo positivo de esta medida lo tenemos en «ARTEXPORT», sociedad comercial formada por cinco fabricantes de calzado, para hacer frente a los gastos de exportación y ofrecer un volumen productivo suficiente.

Mayor uniformidad entre los diferentes sistemas de fabricación...

Así pues, se puede combinar la especialización mesurada con la unidad de pequeñas empresas en cuanto a calidad, precios, denominación común de origen... de modo que, gracias a las facilidades actuales de comunicación, la marginalidad de una situación geográfica no sea un obstáculo importante para un tradicional quehacer artesano-industrial.

\section{FUENTES}

AYUNTAMIENTO DE VALVERDE DEL CAMINO: Memorias municipales de los años 1953 y 1971.

CAMARA DE COMERCIO, INDUSTRIA Y NAVEGACION DE LA PROVINCIA DE HUELVA: Memoria del año 1983.

DELEGACION DE INDUSTRIA DE HUELVA: Archivo geográfico del año 1985. Esta información fue comprobada en entrevistas personales con fabricantes, almacenistas, etc. (CEJUDO LAZO, A., DOMINGUEZ ALONSO, L., FERNANDEZ AZOGIL, M., LAZO PADILLA, P., PARREÑO CRUZ, A., SUAREZ ARROYO, M., VIZCAINO VILLEGAS, R.,...). A todos ellos, y a los que no puedo citar por la brevedad de este trabajo, mi mas expresivo agradecimiento por su valiosa ayuda. Valverde del Camino, 1989.

\section{BIBLIOGRAFIA}

CARAVACA BARROSO, I.: La industria en Sevilla. Publicaciones de la Universidad de Sevilla. Sevilla, 1983.

«Conmemoración del 250 aniversario de la concesión por el rey Felipe V del título de Villa a la ciudad de Valverde del Camino: 1732-1982». Valverde del Camino, 1982. 
Folleto: «La auténtica historia de 38 artesanos de Valverde del Camino». Valverde del Camino, 1978.

LAVADO MONTAÑO, C. y PEREZ REGUERA, I.: Valverde del Camino. Proyecto de análisis de la realidad. Ejemplar mecanografiado. Inédito. Valverde del Camino, 1987.

MORENO PEÑA, N.: La marroquinería en Ubrique. (Cádiz). Memoria de Licenciatura realizada por N.M.P., bajo la dirección de D. Juan BENITO ARRANZ. Universidad de Sevilla. Inédito. Sevilla, 1977.

RAMIREZ COPEIRO DEL VILLAR, J.: Ingleses en Valverde. Huelva, 1985.

RICO PEREZ, A.: «Apuntes para la historia». «Facanías», núms. 46, 47, 51 y 54, 1977.

RICO PEREZ, A.: «Huelva información». Huelva, 1983, 1984.

ROMERO PEREZ, D.: Un pueblo colonizador. Huelva, 1956.

ROMERO PEREZ, M.: «Trabajo domiciliario», «Industrias auxiliares», y «La banquilla». Valverde del Camino, 1974. «La primera fábrica de calzado». «Facanías», núm. 42, 1976. 